\title{
Gay Dating App Users Support and Utilize Sexual Health Features on Apps
}

\author{
Jennifer Hecht ${ }^{1}$ (1) $\cdot$ Maria Zlotorzynska ${ }^{2} \cdot$ Travis H. Sanchez $^{2} \cdot$ Dan Wohlfeiler $^{1}$
}

Accepted: 6 December 2021 / Published online: 11 January 2022

(c) The Author(s) 2022

\begin{abstract}
Men who have sex with men (MSM) frequently meet sex partners through dating apps. Research has demonstrated an association between app use and greater number of sex partners and STIs, but dating apps also pose an opportunity for intervention. By advocating for sexual health features on dating apps, Building Healthy Online Communities (BHOC) aims to increase communication about sexual health among app users. In partnership with Emory University, BHOC added questions to an annual survey of MSM. The questions assessed awareness and uptake of profile fields and sexual health features on the dating apps. Among survey participants, $67 \%(6737 / 10,129)$ reported using dating apps to meet a partner in the past year. Among this group, 77\% (4993/6525) reported awareness of sexual health features. 61\% of app users (2866/4721) who were aware of them reported using one or more sexual health features. BHOC continues to advocate for increased uptake of these features.
\end{abstract}

Keywords MSM $\cdot$ HIV $\cdot$ Sexual health $\cdot$ Internet $\cdot$ Dating apps

\section{Introduction}

Men who have sex with men (MSM) continue to experience a disproportionate burden of HIV infection [1, 2]. MSM were early adopters of using the internet to meet sexual and romantic partners, going back to the early 2000s [3, 4]. The widespread adoption of smartphones and emergence of numerous apps marketed to MSM users has accelerated the popularity of online venues for MSM to connect with each other and in recent years, a very large proportion of MSM report meeting sexual partners online through dating websites or apps [5-7].

Numerous studies, as compiled in one meta-analysis, have explored HIV and sexually transmitted infection (STI) transmission risk among app-using MSM [8]. There is some evidence that MSM who use apps to meet partners are more likely to engage in condomless anal sex, have a higher number of sex partners and experience higher incidence of STIs, such as gonorrhea and chlamydia, as compared to those who

Jennifer Hecht

jenhecht@bhocpartners.org

1 Building Healthy Online Communities, Springboard HealthLab, 5601 Van Fleet Ave, Richmond, CA 94804, USA

2 Rollins School of Public Health, Emory University, 1518 Clifton Road, Atlanta, GA 30322, USA meet partners in-person exclusively $[9,10]$. Other studies are more equivocal and have found that meeting partners online is not predictive of sexual risk behaviors [11-14]. It is also unclear whether meeting partners online promotes highrisk behaviors or merely facilitates these behaviors among those who would be engaging in it regardless of their app use $[15,16]$. Furthermore, previous studies indicate a correlation between app use and increased uptake of sexual health resources, including HIV testing and use of pre-exposure prophylaxis (PrEP) [17, 18]. App users are also more likely to be offered risk assessments for HIV and STI transmission during visits with their healthcare providers [19]. With a high volume of users, an efficient way to facilitate meeting new partners, expand sexual networks and connect users to prevention interventions and messaging, these apps have many features that can facilitate transmission as well as reduce it through providing structural features which facilitate communication among users regarding sexual health.

With the advent of new technologies for identifying and meeting partners, there are new opportunities for MSM to exchange information with partners by using profile options before meeting and/or engaging in sexual activity. Dating apps have increased the number of specific fields for users to share information, both as the apps observe that multiple users are populating open fields with specific sexual health information, and due to advocacy from Building Healthy 
Online Communities, a consortium of public health organizations [20-22]. Sexual health profile options vary from app to app, but usually include some or all of the following: disclosure of HIV status, usage of PrEP, having an undetectable viral load, willingness to use condoms, and date of last HIV and/or STI test. They provide a useful alternative for individuals who may be reticent or find it awkward to discuss these topics verbally with a partner. This can also inform and facilitate risk sorting among men who wish to make a conscious choice about which partners to approach with regards to their sexual practices. In contrast to serosorting, which requires individuals to know their HIV status, users can and do use risk sorting by seeking out partners based on their sexual practices. For example, through viewing others' profiles, a user may or may not choose to have sex with someone based on their sexual health strategies and practices, as well as drug and alcohol usage. Since transmission through a sexual network in part depends on the degree to which users who take occasional risks have sex with someone who takes frequent risks [23], facilitating explicit communication can help reduce unintentional mixing. Profile options also increase communication without relying on ongoing public health human and economic resources to support costly behavioral interventions, which often have low uptake and may reach only a small percentage of app users [24].

As an example, diffusion of innovations theory [25] suggests that app users may be more likely to use PrEP if they see others including it on their profiles. A qualitative study that recruited Black MSM through geo-social apps found that dating apps were a common way for participants to learn about PrEP [26]. Another study found that $42 \%$ of HIVnegative men and $62 \%$ of HIV-positive men had partners they had met through a dating app who disclosed their PrEP usage [27], leading the researchers to draw the conclusion that mobile apps may aid with disclosure of both PrEP and undetectable viral load. While many may benefit from additional information and explicit sexual health communication, these fields are all optional. Giving users the choice of whether or not to disclose behaviors or sexual health risk strategies on apps is important to protect users who may be particularly vulnerable to stigma and persecution.

Building Healthy Online Communities (BHOC) is a consortium of public health leaders and gay dating website and app owners working together to support HIV and STI prevention online. BHOC focuses on structural changes to the apps (such as changing or adding features in the apps) and access to sexual health resources that can support dating app users' sexual health. BHOC has developed ongoing relationships with app owners, and collected data from them to assess their willingness to implement these features. Additionally, BHOC has repeatedly sought input through focus groups and surveys to assess the willingness of app users to utilize them. Collecting data from owners and users is essential for the development of online sexual health promotion strategies.

A formative research survey in 2009 indicated strong levels of support among owners of online dating sites for integrating prevention options into their structures [27]. Additionally, we found that $78 \%$ of MSM users supported the integration of prevention options. These include allowing users to post their sexual health prevention strategies on profiles, facilitating online partner notification options, implementing testing reminders, and providing access to sexual health information and resources. We found that $80 \%$ of users supported having profile options that include HIV status disclosure [20]. More recently, in 2018, a University of Washington study confirmed continued user support for sexual health features, including access to home testing and reminders about sexual health testing [28]. In the present study, we use data from the American Men's Internet Survey (AMIS), a large nationwide online survey of US MSM, to assess awareness and uptake of these features among MSM who use dating apps and analyze differences by demographic and behavioral characteristics.

\section{Methods}

\section{Recruitment and Enrollment}

AMIS conducts data collection annually and aims to collect 10,000 complete surveys from eligible MSM each year and AMIS recruitment methods have been previously reported [29]. Data for the present analysis were taken from the 2018 cycle, which ran from September to November 2018 [30]. Briefly, participants were recruited through convenience sampling from a variety of websites, including dating apps and general social networking websites such as Facebook and Instagram, using banner ads and email blasts to website members (hereafter referred to as "ads"). Participants who completed the survey in previous years were also asked to provide an email address to be invited to complete the present survey. Men who clicked on ads or emailed links were taken directly to the survey website hosted on a secure server administered by SurveyGizmo (Boulder, CO, USA). Participants were eligible to participate if they were age 15 years or older, reported male sex at birth and male gender identity, resided in the United States and provided a US ZIP code, and reported oral and/or anal sex with a male partner at least once in the past. Eligible participants were presented with an electronic informed consent form (or assent form, for those ages 15 to 17) and asked to affirm consent or assent by checking a box in the survey. No incentive was provided for completing the survey. 
Several data cleaning steps were applied to the dataset of eligible responses, as described previously [30]. First, to deduplicate survey responses, demographic data for nearcomplete $(>70 \%)$ survey responses with non-unique internet protocol (IP) addresses were compared, and responses that showed a $100 \%$ match for all characteristics were considered to be duplicate responses. Only the observation with the highest survey completion was retained. Then the dataset was limited to those surveys that were deemed successful, i.e., observations with no missing values for the first question of at least two consecutive sections. Finally, the dataset was restricted to include participants who reported having oral or anal sex in the past 12 months and who provided a valid US ZIP code.

\section{Human Subjects Protection}

The study was conducted in compliance with federal regulations governing protection of human subjects and was reviewed and approved by Emory University's Institutional Review Board. No incentive was provided to the participants. Study data are protected under a federal certificate of confidentiality that prevents legal action to force data release.

\section{Measures}

The primary outcomes in the analysis were awareness and utilization of profile features, which was asked of those participants who earlier in the survey responded that they had used dating websites or mobile phone apps to meet or socialize with other men in the past year. Awareness was assessed with the question, "Do you know that on many apps you can include your preferred sexual health strategy, like condoms, PrEP, or being on treatment for HIV?" Among those who answered "Yes," utilization was assessed with the question, "Did you opt into using the preferred sexual health strategy feature?" Participants who opted into using profile options were also asked about which specific options they displayed on their profiles: condoms, PrEP (for HIV-negative or unknown status participants) and/or taking HIV meds/being undetectable (for participants living with HIV). Participants who indicated that they were not aware of profile features were asked, "Is the preferred sexual health strategy feature one you would like to use in the future?" While not all apps offer all of these features, $85.2 \%$ of participants used the largest app which offers most of these options. Since participants were also asked if they would use the features, those who use apps without those features were still included.

Participant demographic characteristics included age, race/ethnicity, self-reported HIV status, primary language and county of residence population density. Self-reported HIV status was determined from responses to questions about having ever had an HIV test, results of the most recent HIV test and having ever had a positive HIV test. Participants were categorized as self-reported HIV-positive and HIV-negative or unknown status. Participant county of residence was determined from self-reported ZIP code and assigned a population density level from the National Center for Health Statistics (NCHS) 2013 rural-urban classification scheme [31]. We further collapsed these categories into a four-level urbanicity variable: urban (central), suburban (fringe), medium/small metropolitan, and rural (micropolitan and noncore) [32, 33].

Behavioral characteristics were assessed for the 12 months preceding the survey date and included condomless anal intercourse (CAI), number of male oral and/or anal sex partners and partner type. Partner type was categorized as either only main partners (someone the participant felt committed to above anyone else), only casual partners (someone the participant didn't feel committed to or didn't know very well) or both main and casual partners. For HIVnegative or unknown status participants, we assess use of PrEP in the past 12 months. Current antiretroviral therapy (ART) use was assessed for participants who reported living with HIV.

\section{Analyses}

Eligible and consented participants were included in analyses if they had an unduplicated IP address, completed the survey, ever had oral and/or sex with a man in the past 12 months and provided a valid US ZIP code. The analysis sample was further restricted to those who reported using dating websites or mobile phone apps to meet other men in the past 12 months and who answered the survey question about awareness of profile options.

Descriptive statistics of awareness and use of profile options are presented for the analysis sample, and by participant demographic and behavioral characteristics. Frequencies of each type of profile feature (condoms, PrEP and being on HIV medication) reported were calculated among those who reported awareness of profile options.

Modified Poisson models were used to calculate prevalence ratios (PR) and 95\% confidence intervals (CI) for bivariate associations between awareness of profile options and demographic and behavioral characteristics, among the total analysis sample and by HIV status. Characteristics that were significantly associated with awareness were included in a multivariable model to calculate adjusted prevalence ratios (aPR) and 95\% CI. Similar models were used to calculate PRs and aPRs for use of profile options. Statistical significance was determined at $\mathrm{P}<0.05$. All analyses were performed using SAS 9.4 (Cary, NC). 


\section{Results}

Of the 10,129 MSM who answered the AMIS-2018 survey, $6737(66.5 \%)$ reported using dating websites or apps to meet other men in the past 12 months. Of those respondents who answered the questions about awareness of profile options, approximately three quarters (4993/6525, $76.5 \%$ ) responded that they were aware of profile options to indicate preferred sexual health strategies (Table 1). In a multivariable model, age was significantly associated with awareness, with those in the 30-39 age group having the highest awareness as compared to other age groups, and those age 24 and under having the lowest awareness.
Hispanic ethnicity, as compared to non-Hispanic white race, was associated with lower awareness [adjusted prevalence ratio (aPR) 0.95; 95\% Confidence Interval (CI) 0.91, 0.99]. However, overall, the differences in prevalence of awareness between racial and ethnic groups were small (see Table 1). Other characteristics positively associated with awareness of profile options included positive HIV status (aPR 1.09; 95\% CI 1.05, 1.13), recent condomless anal sex (aPR 1.09; 95\% CI 1.05, 1.13), having two or more sex partners in the past year (aPR 1.09; 95\% CI 1.05, 1.13 ), and having only casual partners (aPR 1.08 ; 95\% CI $1.02,1.14$ ) or both main and casual partners (aPR 1.07; $95 \%$ CI 1.01, 1.13). In a separate model that included only participants who were HIV-negative or of unknown status
Table 1 Correlates of awareness of dating application profile options among US MSM who used dating websites or apps to meet men in the past 12 months, American Men's Internet Survey, 2018

\begin{tabular}{|c|c|c|c|c|}
\hline & $\mathrm{N}$ & $\begin{array}{l}\text { Aware of profile } \\
\text { options } \mathrm{n}(\%)\end{array}$ & PR $(95 \%$ CI $)$ & $\mathrm{aPR}(95 \% \mathrm{CI})^{\mathrm{b}}$ \\
\hline Total & 6525 & $4993(76.5)$ & & \\
\hline \multicolumn{5}{|l|}{ Age } \\
\hline $15-17$ & 320 & $178(55.6)$ & $0.68(0.61,0.75)$ & $0.73(0.66,0.81)$ \\
\hline $18-24$ & 2431 & $1682(69.2)$ & $0.84(0.81,0.87)$ & $0.88(0.85,0.91)$ \\
\hline $25-29$ & 860 & $703(81.7)$ & $0.99(0.96,1.03)$ & $1.02(0.98,1.06)$ \\
\hline $30-39$ & 951 & $815(85.7)$ & $1.04(1.01,1.08)$ & $1.06(1.03,1.10)$ \\
\hline 40 and older & 1963 & $1615(82.3)$ & Ref & Ref \\
\hline \multicolumn{5}{|l|}{ Race/Ethnicity } \\
\hline Black, non-Hispanic & 325 & $245(75.4)$ & $0.96(0.90,1.03)$ & $0.95(0.89,1.02)$ \\
\hline Hispanic & 1047 & 750 (71.6) & $0.92(0.88,0.95)$ & $0.94(0.91,0.98)$ \\
\hline White, non-Hispanic & 4561 & $3570(78.3)$ & Ref & Ref \\
\hline Other or multiple races & 488 & 349 (71.5) & $0.91(0.86,0.97)$ & $0.95(0.89,1.00)$ \\
\hline \multicolumn{5}{|l|}{ County population density } \\
\hline Urban & 2405 & $1896(78.8)$ & Ref & Ref \\
\hline Suburban & 1367 & 989 (72.3) & $0.92(0.88,0.95)$ & $0.94(0.90,0.98)$ \\
\hline Small/medium metro & 2141 & $1643(76.7)$ & $0.97(0.94,1.00)$ & $0.99(0.96,1.02)$ \\
\hline Rural & 608 & $463(76.2)$ & $0.97(0.92,1.01)$ & $0.99(0.94,1.04)$ \\
\hline \multicolumn{5}{|l|}{ Primary language } \\
\hline English & 6344 & $4864(76.7)$ & Ref & \\
\hline Spanish & 101 & $72(71.3)$ & $0.93(0.82,1.05)$ & \\
\hline Another language & 50 & $33(66.0)$ & $0.86(0.71,1.05)$ & \\
\hline \multicolumn{5}{|l|}{ HIV status } \\
\hline Positive & 414 & $370(89.4)$ & $1.18(1.14,1.22)$ & $1.09(1.05,1.13)$ \\
\hline Negative/Unknown & 6111 & $4623(75.7)$ & Ref & Ref \\
\hline \multicolumn{5}{|c|}{ Condomless anal sex in past 12 months } \\
\hline Yes & 4661 & $3688(79.1)$ & $1.13(1.09,1.17)$ & $1.09(1.05,1.13)$ \\
\hline No & 1864 & $1305(70.0)$ & Ref & Ref \\
\hline \multicolumn{5}{|c|}{ Sex partners in past 12 months } \\
\hline One & 911 & $580(63.7)$ & Ref & Ref \\
\hline Two or more & 5482 & $4318(78.8)$ & $1.24(1.18,1.30)$ & $1.12(1.06,1.19)$ \\
\hline \multicolumn{5}{|c|}{ Partner type in past 12 months } \\
\hline Main only & 834 & $562(67.4)$ & Ref & Ref \\
\hline Casual only & 2506 & $1913(76.3)$ & $1.13(1.08,1.19)$ & $1.08(1.02,1.14)$ \\
\hline Main and casual & 2982 & $2374(79.6)$ & $1.18(1.12,1.24)$ & $1.07(1.01,1.13)$ \\
\hline
\end{tabular}

Bolded items indicate those that are statistically significant 
Table 2 Correlates of awareness of dating application profile options among US HIVnegative or unknown status MSM who used dating websites or apps to meet men in the past 12 months, American Men's Internet Survey, 2018

\begin{tabular}{|c|c|c|c|c|}
\hline & $\mathrm{N}$ & $\begin{array}{l}\text { Aware of profile } \\
\text { options n (\%) }\end{array}$ & PR $(95 \%$ CI $)$ & $\mathrm{aPR}(95 \% \mathrm{CI})^{\mathrm{b}}$ \\
\hline Total & 6525 & 4993 (76.5) & & \\
\hline \multicolumn{5}{|l|}{ Age } \\
\hline $15-17$ & 319 & $177(55.5)$ & $0.68(0.62,0.76)$ & $0.75(0.67,0.83)$ \\
\hline $18-24$ & 2405 & $1661(69.1)$ & $0.85(0.82,0.88)$ & $0.90(0.87,0.94)$ \\
\hline $25-29$ & 830 & $675(81.3)$ & $1.00(0.96,1.04)$ & $1.03(0.99,1.07)$ \\
\hline $30-39$ & 881 & $749(85.0)$ & $1.05(1.01,1.09)$ & $1.06(1.02,1.10)$ \\
\hline 40 and older & 1676 & $1361(81.2)$ & Ref & Ref \\
\hline \multicolumn{5}{|l|}{ Race/Ethnicity } \\
\hline Black, non-Hispanic & 277 & $205(74.0)$ & $0.96(0.89,1.03)$ & $0.96(0.90,1.04)$ \\
\hline Hispanic & 996 & 704 (70.7) & $0.91(0.87,0.95)$ & $0.94(0.90,0.98)$ \\
\hline White, non-Hispanic & 4271 & $3308(77.5)$ & Ref & Ref \\
\hline Other or multiple races & 469 & $332(70.8)$ & $0.91(0.86,0.97)$ & $0.95(0.90,1.01)$ \\
\hline \multicolumn{5}{|l|}{ County population density } \\
\hline Urban & 2212 & $1728(78.1)$ & Ref & Ref \\
\hline Suburban & 1281 & $910(71.0)$ & $0.91(0.87,0.95)$ & $0.94(0.90,0.98)$ \\
\hline Small/medium metro & 2034 & $1545(76.0)$ & $0.97(0.94,1.00)$ & $1.00(0.97,1.03)$ \\
\hline Rural & 581 & 439 (75.6) & $0.97(0.92,1.02)$ & $1.00(0.95,1.06)$ \\
\hline \multicolumn{5}{|l|}{ Primary language } \\
\hline English & 5938 & $4500(75.8)$ & Ref & \\
\hline Spanish & 96 & $67(69.8)$ & $0.92(0.81,1.05)$ & \\
\hline Another language & 49 & $33(67.3)$ & $0.89(0.73,1.08)$ & \\
\hline \multicolumn{5}{|c|}{ Condomless anal sex in past 12 months } \\
\hline Yes & 4309 & $3372(78.3)$ & $1.13(1.09,1.17)$ & $1.06(1.03,1.10)$ \\
\hline No & 1802 & $1251(69.4)$ & Ref & Ref \\
\hline \multicolumn{5}{|c|}{ Sex partners in past 12 months } \\
\hline One & 884 & $555(62.8)$ & Ref & Ref \\
\hline Two or more & 5100 & $3978(78.0)$ & $1.24(1.18,1.31)$ & $1.12(1.05,1.19)$ \\
\hline \multicolumn{5}{|c|}{ Partner type in past 12 months } \\
\hline Main only & 803 & $535(66.6)$ & Ref & Ref \\
\hline Casual only & 2329 & $1754(75.3)$ & $1.13(1.07,1.19)$ & $1.07(1.01,1.14)$ \\
\hline Main and casual & 2783 & $2197(78.9)$ & $1.18(1.12,1.25)$ & $1.06(0.99,1.12)$ \\
\hline \multicolumn{5}{|l|}{ PrEP use in past 12 months } \\
\hline Yes & 1068 & $976(91.4)$ & $1.27(1.24,1.30)$ & $1.16(1.13,1.20)$ \\
\hline No & 4892 & $3527(72.1)$ & Ref & Ref \\
\hline
\end{tabular}

Bolded items indicate those that are statistically significant
(Table 2), PrEP use in the past year was associated with increased awareness of profile options (aPR 1.16; 95\% CI $1.13,1.20)$. Among participants living with HIV, there were no significant differences in prevalence of awareness between those who were currently taking HIV antiretroviral medication as compared to those who were not (334/374, 89.3\% vs. 32/35, 91.4\%, respectively; PR 0.98; $95 \%$ CI $0.88,1.09)$.

Just over half $(869 / 1532,56.7 \%)$ of participants who were not aware of profile options responded that they would like to use the preferred sexual health strategy features in the future. A substantial proportion of unaware participants
$(207 / 1532,13.5 \%)$ indicated that they did not know if they would use these features.

The prevalence of using profile options among those who were aware of them was $61.1 \%(2866 / 4721)$ (Table 3). In a multivariable model, living in a small/ medium metropolitan or rural county was negatively associated with using profile options (aPR 0.92; 95\% CI $0.87,0.97$ and aPR $0.90,95 \%$ CI 0.83, 0.99, respectively). Having two or more sex partners in the past year was positively associated with using profile options (aPR $1.17 ; 95 \%$ CI 1.06, 1.29). Among participants who were HIV-negative or of unknown status, PrEP use in the past year (Table 4) was associated with increased use of 
Table 3 Correlates of dating application profile options use among US MSM who used dating websites or apps to meet men in the past 12 months and were aware of profile options, American Men's Internet Survey, 2018

\begin{tabular}{|c|c|c|c|c|}
\hline & $\mathrm{N}$ & $\begin{array}{l}\text { Use of profile } \\
\text { options n (\%) }\end{array}$ & PR $(95 \%$ CI $)$ & aPR $(95 \%$ CI $)$ \\
\hline Total & 4721 & $2886(61.1)$ & & \\
\hline \multicolumn{5}{|l|}{ Age } \\
\hline $15-17$ & 159 & $92(57.9)$ & $0.93(0.81,1.07)$ & \\
\hline $18-24$ & 1580 & $930(58.9)$ & $0.95(0.89,1.00)$ & \\
\hline $25-29$ & 676 & $400(59.2)$ & $0.95(0.88,1.02)$ & \\
\hline $30-39$ & 775 & $510(65.8)$ & $1.06(0.99,1.13)$ & \\
\hline 40 and older & 1531 & $954(62.3)$ & Ref & \\
\hline \multicolumn{5}{|l|}{ Race/Ethnicity } \\
\hline Black, non-Hispanic & 230 & $137(59.6)$ & $0.97(0.87,1.08)$ & \\
\hline Hispanic & 709 & $420(59.2)$ & $0.96(0.90,1.03)$ & \\
\hline White, non-Hispanic & 3393 & $2086(61.5)$ & Ref & \\
\hline Other or multiple races & 323 & 199 (61.6) & $1.00(0.92,1.10)$ & \\
\hline \multicolumn{5}{|l|}{ County population density } \\
\hline Urban & 1798 & $1148(63.8)$ & Ref & Ref \\
\hline Suburban & 936 & $583(62.3)$ & $0.98(0.92,1.04)$ & $0.97(0.92,1.04)$ \\
\hline Small/medium metro & 1552 & $907(58.4)$ & $0.92(0.87,0.97)$ & $0.92(0.87,0.97)$ \\
\hline Rural & 433 & $248(57.3)$ & $0.90(0.82,0.98)$ & $0.90(0.83,0.99)$ \\
\hline \multicolumn{5}{|l|}{ Primary language } \\
\hline English & 4600 & $2821(61.3)$ & Ref & \\
\hline Spanish & 69 & $34(49.3)$ & $0.80(0.63,1.02)$ & \\
\hline Another language & 29 & $18(62.1)$ & $1.01(0.76,1.35)$ & \\
\hline \multicolumn{5}{|l|}{ HIV Status } \\
\hline Positive & 356 & $221(62.1)$ & $1.02(0.93,1.11)$ & \\
\hline Negative/Unknown & 4365 & $2665(61.1)$ & Ref & \\
\hline \multicolumn{5}{|c|}{ Condomless anal sex in past 12 months } \\
\hline Yes & 3501 & $2145(61.3)$ & $1.01(0.96,1.06)$ & \\
\hline No & 1220 & $741(60.7)$ & Ref & \\
\hline \multicolumn{5}{|c|}{ Sex partners in past 12 months } \\
\hline One & 544 & $282(51.8)$ & Ref & Ref \\
\hline Two or more & 4088 & $2550(62.4)$ & $1.20(1.11,1.31)$ & $1.17(1.06,1.29)$ \\
\hline \multicolumn{5}{|c|}{ Partner type in past 12 months } \\
\hline Main only & 528 & $292(55.3)$ & Ref & Ref \\
\hline Casual only & 1794 & $1091(60.8)$ & $1.10(1.01,1.20)$ & $1.03(0.93,1.13)$ \\
\hline Main and casual & 2267 & $1425(62.9)$ & $1.14(1.05,1.23)$ & $1.04(0.95,1.14)$ \\
\hline
\end{tabular}

Bolded items indicate those that are statistically significant profile options (aPR 1.48; 95\% CI 1.42, 1.56). Among participants living with HIV, there were no significant differences in use of profile options between those who were currently taking HIV antiretroviral medication as compared to those who were not $(204 / 322,63.4 \%$ vs. 16/30, 53.3\%, respectively; PR 1.19; 95\% CI 0.84, 1.68).

Of all participants who included any sexual health strategy on their profile, approximately half (1430/2886, $49.5 \%)$ indicated that they used condoms. The vast majority $(665 / 776,85.7 \%)$ of participants who took PrEP in the past year and opted into any profile options included
PrEP use on their profile. Two-thirds (136/204, 66.7\%) of participants who took HIV antiretroviral therapy and opted into any profile options included HIV medications/ undetectable viral load on their profile.

\section{Discussion}

In a national, cross-sectional survey of internet-using MSM, we found a high degree of awareness and use of dating profile options to disclose preferred strategies for 
Table 4 Correlates of dating application profile options use among US HIV-negative or unknown status MSM who used dating websites or apps to meet men in the past 12 months and were aware of profile options, American Men's Internet Survey, 2018

\begin{tabular}{|c|c|c|c|c|}
\hline & $\mathrm{N}$ & $\begin{array}{l}\text { Use of profile } \\
\text { options n (\%) }\end{array}$ & PR $(95 \%$ CI $)$ & aPR $(95 \%$ CI $)$ \\
\hline Total & 4365 & $2665(61.1)$ & & \\
\hline \multicolumn{5}{|l|}{ Age } \\
\hline $15-17$ & 158 & $91(57.6)$ & $0.93(0.81,1.07)$ & \\
\hline $18-24$ & 1560 & $917(58.8)$ & $0.95(0.89,1.01)$ & \\
\hline $25-29$ & 648 & $388(59.9)$ & $0.97(0.90,1.04)$ & \\
\hline $30-39$ & 714 & $473(66.2)$ & $1.07(1.00,1.14)$ & \\
\hline 40 and older & 1285 & $796(61.9)$ & Ref & \\
\hline \multicolumn{5}{|l|}{ Race/Ethnicity } \\
\hline Black, non-Hispanic & 190 & $115(60.5)$ & $0.99(0.88,1.11)$ & \\
\hline Hispanic & 664 & $395(59.5)$ & $0.97(0.91,1.04)$ & \\
\hline White, non-Hispanic & 3142 & $1926(61.3)$ & Ref & \\
\hline Other or multiple races & 307 & $188(61.2)$ & $1.00(0.91,1.10)$ & \\
\hline \multicolumn{5}{|l|}{ County population density } \\
\hline Urban & 1637 & $1048(64.0)$ & Ref & Ref \\
\hline Suburban & 861 & $535(62.1)$ & $0.97(0.91,1.03)$ & $1.02(0.96,1.09)$ \\
\hline Small/medium metro & 1455 & $846(58.1)$ & $0.91(0.86,0.96)$ & $0.97(0.92,1.03)$ \\
\hline Rural & 411 & $236(57.4)$ & $0.90(0.82,0.98)$ & $0.98(0.89,1.07)$ \\
\hline \multicolumn{5}{|l|}{ Primary language } \\
\hline English & 4249 & $2601(61.2)$ & Ref & \\
\hline Spanish & 65 & $33(50.8)$ & $0.83(0.65,1.05)$ & \\
\hline Another language & 29 & $18(62.1)$ & $1.01(0.76,1.35)$ & \\
\hline \multicolumn{5}{|c|}{ Condomless anal sex in past 12 months } \\
\hline Yes & 3196 & $1958(61.3)$ & $1.01(0.96,1.07)$ & \\
\hline No & 1169 & $707(60.5)$ & Ref & \\
\hline \multicolumn{5}{|c|}{ Sex partners in past 12 months } \\
\hline One & 519 & $267(51.4)$ & Ref & Ref \\
\hline Two or more & 3762 & $2346(62.4)$ & $1.21(1.11,1.32)$ & $1.13(1.02,1.26)$ \\
\hline \multicolumn{5}{|c|}{ Partner type in past 12 months } \\
\hline Main only & 501 & $276(55.1)$ & Ref & Ref \\
\hline Casual only & 1641 & $998(60.8)$ & $1.10(1.01,1.21)$ & $1.01(0.92,1.11)$ \\
\hline Main and casual & 2098 & $1317(62.8)$ & $1.14(1.05,1.24)$ & $0.99(0.90,1.09)$ \\
\hline \multicolumn{5}{|l|}{ PrEP use in past 12 months } \\
\hline Yes & 951 & $776(81.6)$ & $1.48(1.42,1.55)$ & $1.46(1.40,1.53)$ \\
\hline No & 3316 & $1826(55.1)$ & Ref & Ref \\
\hline
\end{tabular}

Bolded items indicate those that are statistically significant decreasing HIV and STI transmission risk. There was some demographic variability in knowledge of and uptake of these profile options, with users under the age of 25 reporting significantly lower awareness. As young MSM are a highly vulnerable population with respect to HIV and STI infection [34, 35] and also use dating apps to meet partners at higher rates than older MSM [8], increasing knowledge of these options may benefit young MSM by increasing sexual health communications between potential partners. Indeed, among those MSM who were aware of profile options, use of these options was not significantly different among younger users as compared to other age groups. We also found slightly lower awareness among Hispanic users. Although participant language was not found to be significantly associated with knowledge of these profile options, this may be due to the survey only being administered in English, and the number of users who indicated a primary language other than English was small. Those who lived in more rural areas were less likely to indicate use of profile options, possibly attributable to privacy concerns in areas with smaller populations of MSM. However, these differences were minor. Thus, these findings reveal high levels of acceptance among a large proportion of dating app users, and that many users may benefit from increased uptake of these dating profile options [27]. 
More substantial differences in uptake were found regarding HIV status and self-reported sexual behaviors. The greatest proportion of app users who were aware of the sexual health profile options were those who reported taking PrEP. This may be due to their interest in having sex without condoms, which may increase their desirability in the sexual marketplace among some gay men [36-38] or to communicate their health strategy to others. Usage was also highest among PrEP users, and of all specific profile options that we asked about, PrEP use was the feature that had the highest level of uptake. Awareness of profile options was significantly higher among participants who reported living with HIV, engaged in condomless anal sex, or had two or more partners and had casual sex partners. Usage was significantly higher only among those with multiple partners. This may be due to higher usage generally of apps among those who have multiple sex partners over the course of a year. Notably, no significant differences in awareness or use were found among participants living with HIV who were on ART, as compared to those who were not, but this may be due to the small number of HIV-positive participants who were not taking ART. There may be many motivations for disclosing HIV status; for example, in formative surveys gathered by BHOC, many HIV-positive users indicated wanting to identify other HIV-positive partners.

Another key finding is that over half of the participants who were not aware of profile options were interested in using them. This suggests that increased adoption of these features, especially among younger users, could be achieved by the apps increasing awareness of the options and their benefits through promotional efforts.

Dating apps are now used by the vast majority of MSM $[7,39,40]$, and with their large number of users, they present an opportunity for intervention to reduce HIV and STI transmission at the population level. Much like gay bars and sex clubs have served as partners for behavioral and structural HIV education and prevention efforts since the earliest days of the epidemic [41, 42], dating apps for MSM can play a critical role in these efforts, especially in the context of a decline in physical venues in which MSM socialize [43].

With $67 \%$ of MSM reporting app use within the past year to meet a partner, nearly 2.6 million of the estimated 4 million MSM in the US could benefit from increased utilization of the sexual health options offered on the apps [33]. While our findings indicate significant uptake among MSM to an estimated 1.1 million users, there is still much room for improving uptake. The higher the proportion of app users who complete these fields, the easier it will be to normalize the sharing of sexual health information, and the easier it will be for app users to identify partners whose prevention preferences match their own.

It is essential to point out that these fields are all optional, and that completing them may not always be in the best interest of the user. HIV-related stigma remains prevalent within MSM communities [44]. Many people may be uncomfortable publicly posting personal information about their sexual preferences and health due to concerns over privacy and unintended disclosure to other parties, especially within communities with high levels of sexual identity stigma [45] and younger users who may not have disclosed their sexual identity to family or social circle [46]. Furthermore, the terms of service for apps generally prohibit users under the age of 18 , which makes efforts to increase awareness of profile options among minors who access the apps challenging. MSM may also have perceived and real safety concerns about encountering judgement or harassment from other users on the app, and this may lead to their choice not to use some of these features [47]. Apps should provide information in prominent places within the app that allows users to make informed choices regarding posting their sexual health information. Having these fields helps to normalize information sharing, and still allows users to opt out of using them.

Users may not be truthful about their information on a profile or keep their information up-to-date. While there is no perfect way to ensure honesty, app users should always be encouraged to treat the information received through the profile as the beginning of further conversation, and ideally continue to exchange more information via text or in-person before meeting up and/or engaging in sexual activity. Since many users may change their sexual health strategies over time, apps should support the posting and updating of accurate information by encouraging users to get tested and to review, and where necessary update, their information every 3 months.

We note several limitations to the present study. First, these data were collected through an online convenience sampling approach and may not be generalizable to all MSM in the US or all MSM online. Second, in some cases our terminology may not have been clear to study participants. For example, the term "prevention strategies" may not have been a term that all participants know. Third, while participant language was not found to be significantly associated with knowledge of profile options, this may be due to the fact that the survey was only administered in English. Fourth, data from this survey were collected in 2018. While three years is a substantial amount of time in the context of rapidly changing dating app technology, we have noted few structural changes in sexual health profile features available in apps since that time. Finally, not all apps have the same profile options available to users. While most of the apps include sexual health options as part of users' profiles, apps differ in which options are included, and the wording of each option. 


\section{Conclusions}

$\mathrm{BHOC}$ has used data from users to prioritize and promote strategies on dating apps that are sustainable and reach high numbers of users, and require no or little ongoing investment by public health programs in order to create environments for MSM that support health-promoting behaviors [48]. These include new sexual health profile fields, sexual health testing reminders, links to partner notification services, testing, and other sexual health resources. BHOC hopes to increase use of sexual health profile fields and access to sexual health information by promoting usage of profile fields and testing reminders among those apps which have already implemented these features, and partnering with more dating apps who have not yet implemented them. Additionally, BHOC is encouraging apps to provide links to health information in prominent locations on apps, so we can increase usage. This research provides guidance for understanding the factors associated with uptake that can be used to guide both public health communication and ongoing conversations with apps about their support of sexual health.

As we work to implement these changes, we recognize additional research using qualitative methods to better understand user concerns about sexual health fields will enhance our interpretation of the data. We also encourage future research to include epidemiological modeling to determine the percentage of sexual health profile options that need to be completed in order to have the maximum population-level impact on transmission, by facilitating users making informed choices regarding sexual health practices with new partners.

Acknowledgements We would like to thank participants of the AMIS survey as well as the dating apps and websites who partner with us to promote the health of their users.

Funding Funding was provided by National Institutes of Health (P30AI050409, MAC AIDS Fund).

Open Access This article is licensed under a Creative Commons Attribution 4.0 International License, which permits use, sharing, adaptation, distribution and reproduction in any medium or format, as long as you give appropriate credit to the original author(s) and the source, provide a link to the Creative Commons licence, and indicate if changes were made. The images or other third party material in this article are included in the article's Creative Commons licence, unless indicated otherwise in a credit line to the material. If material is not included in the article's Creative Commons licence and your intended use is not permitted by statutory regulation or exceeds the permitted use, you will need to obtain permission directly from the copyright holder. To view a copy of this licence, visit http://creativecommons.org/licenses/by/4.0/.

\section{References}

1. Singh S, Song R, Johnson AS, McCray E, Hall HI. HIV incidence, prevalence, and undiagnosed infections in U.S. men who have sex with men. Ann Intern Med. 2018;168(10):685-94.

2. Centers for Disease Control and Prevention. Estimated HIV incidence and prevalence in the United States, 2010-2016. https:// www.cdc.gov/hiv/pdf/library/reports/surveillance/cdc-hiv-surve illance-supplemental-report-vol-24-1.pdf. Accessed 22 Apr 2021.

3. Bull SS, McFarlane M, Lloyd L, Rietmeijer C. The process of seeking sex partners online and implications for STD/HIV prevention. AIDS Care. 2004;16(8):1012-20.

4. Kim AA, Kent C, McFarland W, Klausner JD. Cruising on the Internet highway. J Acquir Immune Defic Syndr. 2001;28(1):89-93.

5. Duncan DT, Park SH, Hambrick HR, Dangerfield Ii DT, Goedel WC, Brewer R, Mgbako O, Lindsey J, Regan SD, Hickson DA. Characterizing geosocial-networking app use among young black men who have sex with men: A multi-city cross-sectional survey in the southern United States. JMIR mHealth uHealth. 2018;6(6):e10316.

6. Grov C, Breslow AS, Newcomb ME, Rosenberger JG, Bauermeister JA. Gay and bisexual men's use of the Internet: research from the 1990s through 2013. J Sex Res. 2014;51(4):390-409.

7. Paz-Bailey G, Hoots BE, Xia M, Finlayson T, Prejean J, Purcell DW, Group NS. Trends in internet use among men who have sex with men in the United States. J Acquir Immune Defic Syndr. 2017;75(Suppl 3):S288-95.

8. Zou H, Fan S. Characteristics of men who have sex with men who use smartphone geosocial networking applications and implications for HIV interventions: a systematic review and meta-analysis. Arch Sex Behav. 2017;46(4):885-94.

9. Kachur RE, Copen CE, Strona FV, Bernstein KT, Furness BW, Hogben M. Factors associated with online sex partners among gay, bisexual and other men who have sex with men: Results from a national survey. Sex Transm Dis. 2021;48(8):542.

10. Beymer MR, Weiss RE, Bolan RK, Rudy ET, Bourque LB, Rodriguez JP, Morisky DE. Sex on demand: geosocial networking phone apps and risk of sexually transmitted infections among a cross-sectional sample of men who have sex with men in Los Angeles County. Sex Transm Infect. 2014;90(7):567-72.

11. Whitfield DL, Kattari SK, Walls NE, Al-Tayyib A. Grindr, Scruff, and on the hunt: predictors of condomless anal Sex, internet use, and mobile application use among men who have sex with men. Am J Mens Health. 2017;11(3):775-84.

12. Jenness SM, Neaigus A, Hagan H, Wendel T, Gelpi-Acosta C, Murrill CS. Reconsidering the internet as an HIV/STD risk for men who have sex with men. AIDS Behav. 2010;14(6):1353-61.

13. Chiasson MA, Hirshfield S, Remien RH, Humberstone M, Wong T, Wolitski RJ. A comparison of on-line and off-line sexual risk in men who have sex with men: an event-based on-line survey. $\mathrm{J}$ Acquir Immune Defic Syndr. 2007;44(2):235-43.

14. Holloway IW, Dunlap S, del Pino HE, Hermanstyne K, Pulsipher $\mathrm{C}$, Landovitz RJ. Online social networking, sexual risk and protective behaviors: considerations for clinicians and researchers. Curr Addict Rep. 2014;1(3):220-8.

15. DeVost MA, Beymer MR, Weiss RE, Shover CL, Bolan RK. Appbased sexual partner seeking and sexually transmitted infection outcomes: a cross-sectional study of HIV-negative men who have sex with men attending a sexually transmitted infection clinic in Los Angeles, California. Sex Transm Dis. 2018;45(6):394-9.

16. Mustanski BS. Are sexual partners met online associated with HIV/STI risk behaviours? Retrospective and daily diary data in conflict. AIDS Care. 2007;19(6):822-7. 
17. Hoenigl M, Little SJ, Grelotti D, Skaathun B, Wagner GA, Weibel N, Stockman JK, Smith DM. Grindr users take more risks, but are more open to Human Immunodeficiency Virus (HIV) preexposure prophylaxis: could this dating app provide a platform for HIV prevention outreach? Clin Infect Dis. 2020;71(7):e135-40.

18. Rosengren AL, Davy-Mendez T, Hightow-Weidman LB. Online sex partner seeking and HIV testing frequency among young Black sexual minority men. J HIV AIDS Soc Serv. 2020;19(1):42-54.

19. Noble M, Jones AM, Bowles K, DiNenno EA, Tregear SJ. HIV testing among internet-using MSM in the United States: systematic review. AIDS Behav. 2017;21(2):561-75.

20. Wohlfeiler D, Hecht J. Partnering with dating app owners to reduce HIV and STD transmission. National HIV Prevention Conference. Atlanta, Georgia, USA, March 18-21, 2019 (abstract 5746).

21. Wohlfeiler D, Hecht J, Raymond HF, Kennedy T, McFarland W. How can we improve HIV and STD prevention online for MSM? Assessing the preferences of website owners, website users, and HIV/STD directors. https://www.ncsddc.org/wp-content/uploads/ 2017/08/how_can_we_improve_hiv_and_std_prevention_online_ for_msm_full_report_0.pdf. Accessed 26 Feb 2021.

22. Wohlfeiler D, Hecht J, Volk J, Fisher Raymond H, Kennedy T, McFarland W. How can we improve online HIV and STD prevention for men who have sex with men? Perspectives of hook-up website owners, website users, and HIV/STD directors. AIDS Behav. 2013;17(9):3024-33.

23. Wohlfeiler D, Potterat JJ. Using gay men's sexual networks to reduce sexually transmitted disease (STD)/human immunodeficiency virus (HIV) transmission. Sex Transm Dis. 2005;32(10 Suppl):S48-52.

24. Sanchez T, Finlayson T, Drake A, Behel S, Cribbin M, Dinenno E, Hall T, Kramer S, Lansky A. Human immunodeficiency virus (HIV) risk, prevention, and testing behaviors-United States, National HIV Behavioral Surveillance System: men who have sex with men, November 2003-April 2005. Morb Mortal Wkly Rep. 2006;55(6):1-16.

25. Rogers E. Diffusion of innovations. 5th ed. New York: Free Press; 2003.

26. Fields EL, Thornton N, Long A, Morgan A, Uzzi M, Sanders RA, Jennings JM. Young black MSM's exposures to and discussions about PrEP while navigating geosocial networking apps. J LGBT Youth. 2021;18(1):23-39.

27. Newcomb ME, Mongrella MC, Weis B, McMillen SJ, Mustanski B. Partner disclosure of PrEP use and undetectable viral load on geosocial networking apps: frequency of disclosure and decisions about condomless sex. J Acquir Immune Defic Syndr. 2016;71(2):200-6.

28. Contesse MG, Fredericksen RJ, Wohlfeiler D, Hecht J, Kachur R, Strona FV, Katz DA. Acceptability of using geosocial networking applications for HIV/sexually transmitted disease partner notification and sexual health services. Sex Transm Dis. 2020;47(1):41-7.

29. Sanchez TH, Sineath RC, Kahle EM, Tregear SJ, Sullivan PS. The Annual American Men's Internet Survey of behaviors of men who have sex with men in the United States: Protocol and key indicators report 2013. JMIR Public Health Surveill. 2015;1(1):e3.

30. Wiatrek S, Zlotorzynska M, Rai R, Sullivan P, Sanchez T. The Annual American Men's Internet Survey of behaviors of men who have sex with men in the United States: Key indicators report 2018. JMIR Public Health Surveill. 2021;7(3):e21812.

31. Ingram DD, Franco SJ. 2013 NCHS urban-rural classification scheme for counties. Vital Health Stat. 2014;2(166):1-73.

32. Oster AM, Sternberg M, Lansky A, Broz D, Wejnert C, Paz-Bailey G. Population size estimates for men who have sex with men and persons who inject drugs. J Urban Health. 2015;92(4):733-43.

33. Grey JA, Bernstein KT, Sullivan PS, Purcell DW, Chesson HW, Gift TL, Rosenberg ES. Estimating the population sizes of men who have sex with men in US states and counties using data from the American Community Survey. JMIR Public Health Surveill. 2016;2(1):e14.

34. Centers for Disease Control and Prevention. Sexually transmitted disease surveillance, 2019. Atlanta: U.S. Department of Health and Human Services; 2021.

35. Centers for Disease Control and Prevention. HIV surveillance report, 2019. Atlanta: U.S. Department of Health and Human Services; 2021.

36. Medina MM, Crowley C, Montgomery MC, Tributino A, Almonte A, Sowemimo-Coker G, Nunn A, Chan PA. Disclosure of HIV serostatus and pre-exposure prophylaxis use on internet hookup sites among men who have sex with men. AIDS Behav. 2019;23(7):1681-8.

37. Martinez JE, Jonas KJ. Pre-exposure prophylaxis sorting among men who have sex with men. AIDS Care. 2019;31(3):388-96.

38. Warner M, Maestre JF, Gibbs J, Chung C-F, Blandford A. Signal appropriation of explicit HIV status disclosure fields in sex-social apps used by gay and bisexual men. In: Proceedings of the 2019 CHI Conference on Human Factors in Computing Systems - CHI '19: May 4-9, 2019, Glasgow, Scotland, UK. ACM. p 692.

39. Benotsch EG, Kalichman S, Cage M. Men who have met sex partners via the Internet: prevalence, predictors, and implications for HIV prevention. Arch Sex Behav. 2002;31(2):177-83.

40. Badal HJ, Stryker JE, DeLuca N, Purcell DW. Swipe right: dating website and app use among men who have sex with men. AIDS Behav. 2018;22(4):1265-72.

41. Woods WJ, Euren J, Pollack LM, Binson D. HIV prevention in gay bathhouses and sex clubs across the United States. J Acquir Immune Defic Syndr. 2010;55(Suppl 2):S88-90.

42. Kalichman SC. Social and structural HIV prevention in alcoholserving establishments: review of international interventions across populations. Alcohol Res Health. 2010;33(3):184-94.

43. Mattson G. Are gay bars closing? Using business listings to infer rates of gay bar closure in the United States, 1977-2019. Socius. 2019;5:2378023119894832.

44. Smit PJ, Brady M, Carter M, Fernandes R, Lamore L, Meulbroek M, Ohayon M, Platteau T, Rehberg P, Rockstroh JK, Thompson M. HIV-related stigma within communities of gay men: a literature review. AIDS Care. 2012;24(4):405-12.

45. Hubach RD, O’Neil A, Stowe M, Giano Z, Curtis B, Fisher CB. Perceived confidentiality risks of mobile technology-based ecologic momentary assessment to assess high-risk behaviors among rural men who have sex with men. Arch Sex Behav. 2020;50(4):1641-50.

46. Flores D, Docherty SL, Relf MV, McKinney RE, Barroso JV. "It's almost like gay sex doesn't exist": parent-child sex communication according to gay, bisexual, and queer adolescent sons. J Adolesc Res. 2019;34(5):528-62.

47. Lauckner C, Truszczynski N, Lambert D, Kottamasu V, Meherally S, Schipani-McLaughlin AM, Taylor E, Hansen N. "Catfishing", cyberbullying, and coercion: an exploration of the risks associated with dating app use among rural sexual minority males. J Gay Lesbian Ment Health. 2019;23(3):289-306.

48. Kaufman MR, Cornish F, Zimmerman RS, Johnson BT. Health behavior change models for HIV prevention and AIDS care: practical recommendations for a multi-level approach. J Acquir Immune Defic Syndr. 2014;66(Suppl 3):S250-8.

Publisher's Note Springer Nature remains neutral with regard to jurisdictional claims in published maps and institutional affiliations. 